\title{
Cd in Jiaozhou Bay is sourced from river flow, marine current and atmosphere deposition
}

\author{
Dongfang Yang ${ }^{1,2, a}$, Zhenqing Miao ${ }^{3, \text { b, c }}$, Xiaolong Zhang', Qi Wang ${ }^{1}$, Haixia Li ${ }^{1}$ \\ ${ }^{1}$ Accountancy Shool, Xijing University, Xian 710123, China \\ ${ }^{2}$ North China Sea Environmental Monitoring Center, SOA, Qingdao 266033, China \\ ${ }^{3}$ College of Fisheries, Zhejiang Ocean University, Zhoushan, 316022, China \\ adfyang_dfyang@126.com, ${ }^{b}$ corresponding author, ${ }^{c}$ mzq@zjou.edu.cn.
}

Keywords: Cadmium (Cd), River flow, Atmospheric deposition, Marine current, Jiaozhou Bay.

\begin{abstract}
Many marine bays have been polluted by many pollutants, and identifying the major pollution sources is essential to pollution control. This paper analyzed the distribution and pollution source of Cd in Jiaozhou Bay in 1988. Results showed that Cd contents in surface waters in Jiaozhou Bay in April, July and October 1988 were $0.09-0.12 \mu \mathrm{g} \mathrm{L}^{-1}, 0.10-1.07 \mu \mathrm{g} \mathrm{L}{ }^{-1}$ and $0.03-0.040 \mu \mathrm{g} \mathrm{L}^{-1}$, respectively. This bay had been slight contaminated by $\mathrm{Cd}$ in 1988 . The major sources of Cd were river flow, marine current, and atmospheric deposition, whose source strengths were $1.07 \mu \mathrm{g} \mathrm{L}^{-1}, 0.12 \mu \mathrm{g} \mathrm{L}^{-1}$ and $0.04 \mu \mathrm{g} \mathrm{L}^{-1}$, respectively. River flow was the major Cd source in 1988 since a big part of $\mathrm{Cd}$ generated by human activities were washed to and delivered by river flow, and discharged to marine bay finally. Finally, a block diagram model was provided to described these three input paths via land, ocean and atmosphere.
\end{abstract}

\section{Introduction}

Cd is one of the widely used heavy metal elements, and the use amount of Cd has been increasing along with the rapid increasing of industry [1-3]. As a result, the land, ocean and atmosphere a polluted by $\mathrm{Cd}$, and the excessive existence of $\mathrm{Cd}$ is harmful to human and ecosystem since $\mathrm{Cd}$ in high toxic [4-5]. Hence, identifying the major source of $\mathrm{Cd}$ is essential to pollution control.

Jiaozhou Bay is a semi-closed bay located in Shandong Province, China, and has been polluted by various pollutants including $\mathrm{Cd}$ in the past decades [6-7]. Based on investigation on $\mathrm{Cd}$ in surface waters in April, July and October 1988 in Jiaozhou Bay, the aim of this paper is to identify the pollution source of $\mathrm{Cd}$, and to provide basic information for scientific research and pollution control.

\section{Study area and data collection}

Jiaozhou Bay is located in the south of Shandong Province, eastern China $\left(35^{\circ} 55^{\prime}-36^{\circ} 18^{\prime} \mathrm{N}\right.$, $120^{\circ} 04^{\prime}-120^{\circ} 23^{\prime} \mathrm{E}$ ), with the total area and average water depth of $446 \mathrm{~km}^{2}$ and $7 \mathrm{~m}$, respectively. The bay mouth is very narrow $(3 \mathrm{~km})$, and is connected to the Yellow Sea. There are a dozen of rivers including Dagu River, Haibo Rriver, Licun Rriver, and Loushan Rriver etc., all of which are seasonal rivers [8-9].

The investigation on Cd in surface waters in Jiaozhou Bay was carried on in April, July and October 1988. In April and July, there were 13 monitoring sites (i.e., 31, 32, 33, 34, 35, 36, 84, 85, 86, 87, 88, 89 and 90), while in October there were 6 monitoring sites (i.e., 84, 85, 86, 87, 88, and 89) (Fig. 1). Cd in waters was sampled and monitored follow by National Specification for Marine Monitoring [10]. 


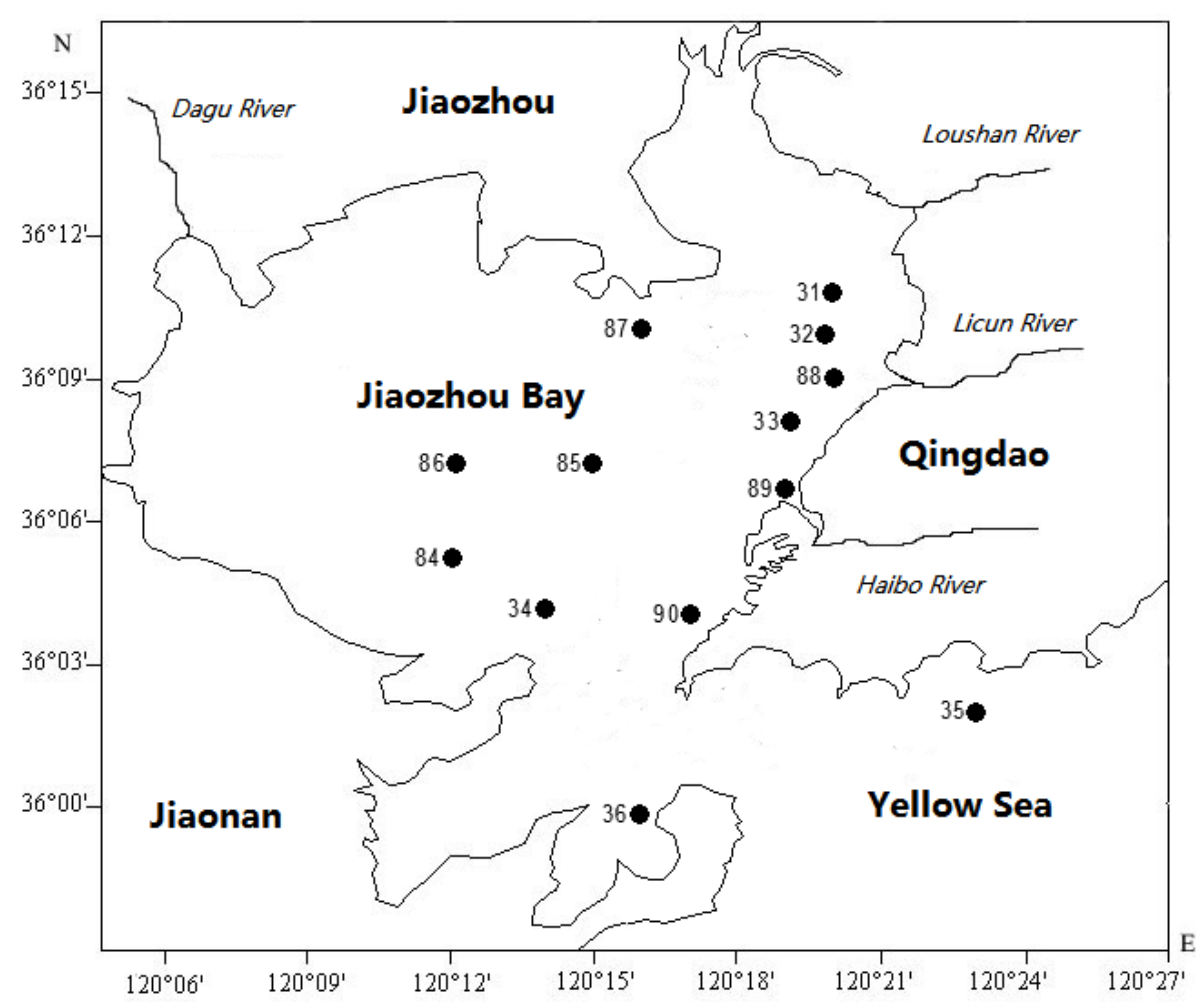

Fig. 1 Geographic location and sampling sites of Jiaozhou Bay

\section{Results and discussion}

\subsection{Contents and pollution level}

Cd contents in surface waters in Jiaozhou Bay in April, July and October 1988 were 0.09-0.12 $\mu \mathrm{g}$ $\mathrm{L}^{-1}, 0.10-1.07 \mu \mathrm{g} \mathrm{L}^{-1}$ and $0.03-0.04 \mu \mathrm{g} \mathrm{L}^{-1}$, respectively (Table 1). In according Sea Water Quality Standard (GB3097-1997), the pollution levels of Cd in Jiaozhou Bay in 1988 were still slight. April, July and October were spring, summer and autumn in study area. It could be found that Cd contents in Jiaozhou Bay were in order of summer>spring>autumn. Meanwhile, Cd contents in these different seasons were different in one order of magnitude. This indicated that the seasonal variations of Cd was remarkable.

Table 1 Cd contents and pollution levels in surface waters in Jiaozhou Bay 1988

\begin{tabular}{cccc}
\hline Month & April & July & October \\
\hline Cd content $/ \mu \mathrm{g} \mathrm{L}^{-1}$ & $0.09-0.12$ & $0.10-1.07$ & $0.03-0.04$ \\
Grade & I & I, II & I \\
\hline
\end{tabular}

\subsection{Horizontal distributions of Cd}

In April 1988, high value $\left(0.12 \mu \mathrm{g} \mathrm{L}^{-1}\right)$ of Cd contents in surface waters was occurring in Site 35 in the open waters, and $\mathrm{Cd}$ contents were decreasing from the high value center to the bay mouth $\left(0.09 \mu \mathrm{g} \mathrm{L}^{-1}\right)$ (Fig. 2). In July 1988, high value $\left(1.07 \mu \mathrm{g} \mathrm{L}^{-1}\right)$ of Cd contents in surface waters was occurring in Site 89 in the estuary of Haibo River, and Cd contents were decreasing from the high value center to all round, i.e., to the bay center $\left(0.45 \mu \mathrm{g} \mathrm{L}^{-1}\right)$, to the coastal waters in the south $(0.10$ $\mu \mathrm{g} \mathrm{L}^{-1}$ ) (Fig. 3). In October 1988, high value $\left(0.04 \mu \mathrm{g} \mathrm{L}^{-1}\right)$ of Cd contents in surface waters was occurring in Site 85 in the center of the bay, and Cd contents were decreasing from the center of the bay to to all round $\left(0.03 \mu \mathrm{g} \mathrm{L}^{-1}\right)$ (Fig. 4). The variations of the horizontal distributions of Cd indicated that there may be different source and were responding in different seasons. 


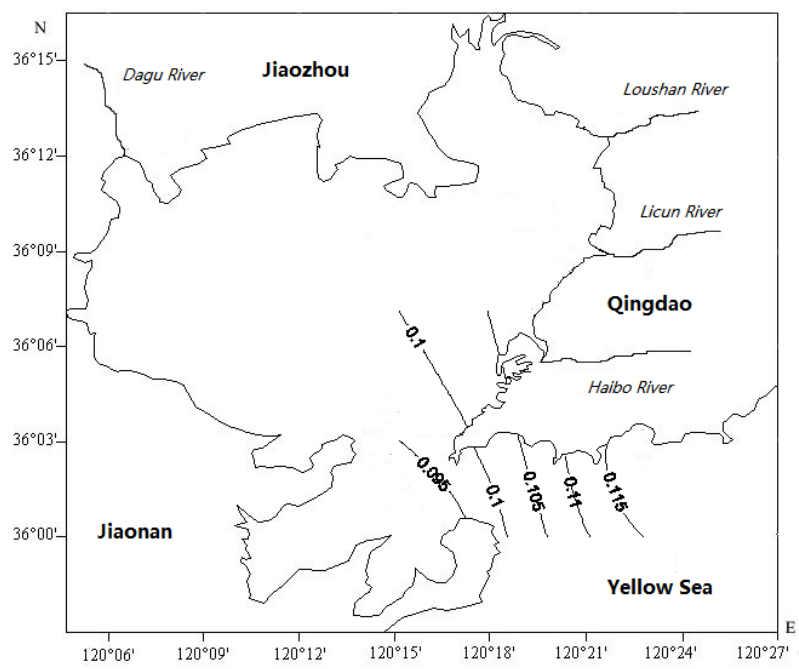

Fig. 2 Horizontal distribution of Cd in surface waters in Jiaozhou Bay in April $1988 / \mu \mathrm{g}$ L-1

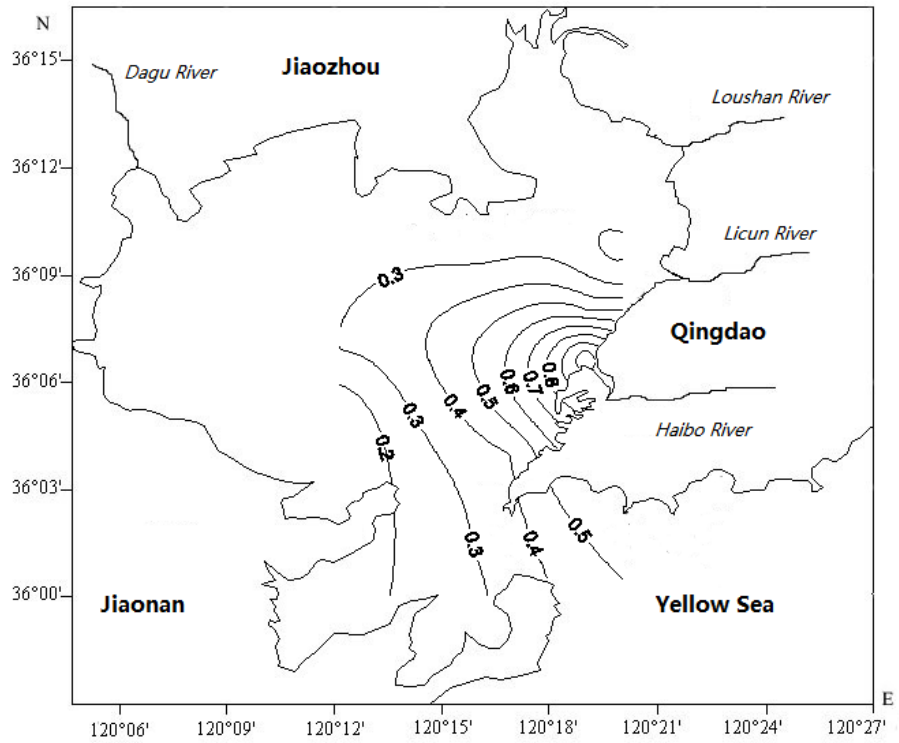

Fig. 3 Horizontal distribution of Cd in surface waters in Jiaozhou Bay in July 1988 / $\mu$ g L-1

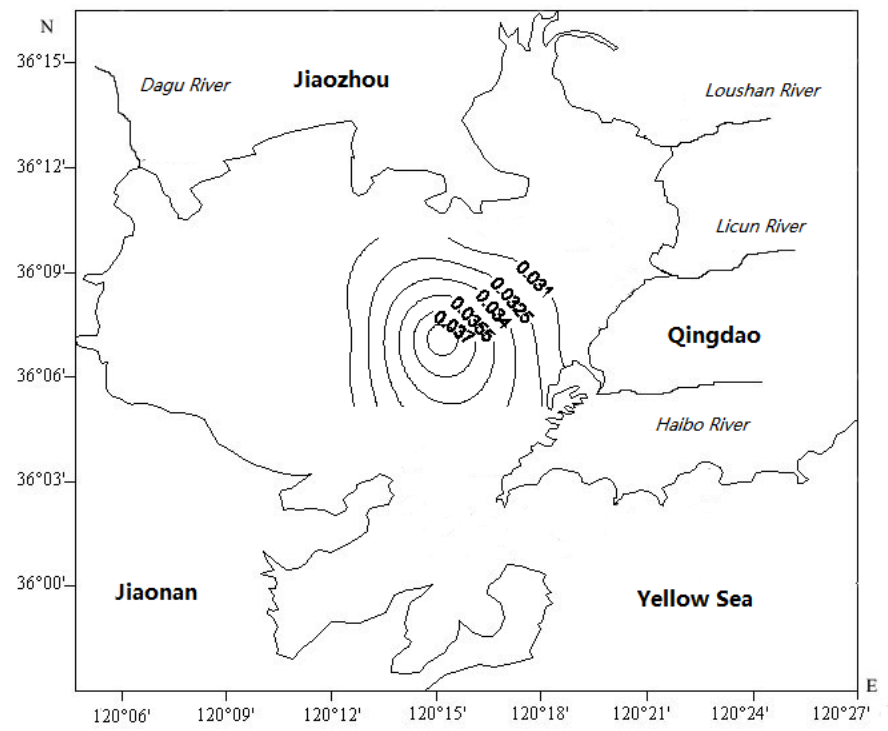

Fig. 4 Horizontal distribution of Cd in surface waters in Jiaozhou Bay in October $1988 / \mu \mathrm{g}$ L-1 


\subsection{Sources of $\mathbf{C d}$.}

In according to the horizontal distributions of $\mathrm{Cd}$, it could be identified that the major sources of Cd were river flow, marine current, and atmospheric deposition, whose source strengths were 1.07 $\mu \mathrm{g} \mathrm{L}{ }^{-1}, 0.12 \mu \mathrm{g} \mathrm{L}^{-1}$ and $0.04 \mu \mathrm{g} \mathrm{L}^{-1}$, respectively. The source strength of river was still slight that confirmed to Grade II in 1988, while the source strengths of marine current and atmosphere deposition were very weak that confirmed to Grade I. In comparison, the source strength of river flow was about one order of magnitude higher than the source strength of marine current, and the source strength of marine current was about one order of magnitude higher than the source strength of atmosphere deposition. The horizontal variations of Cd contents in Jiaozhou Bay were mainly determined by these different major sources via land, ocean and atmosphere, and the migration processes were described in a block diagram model in Fig. 5.

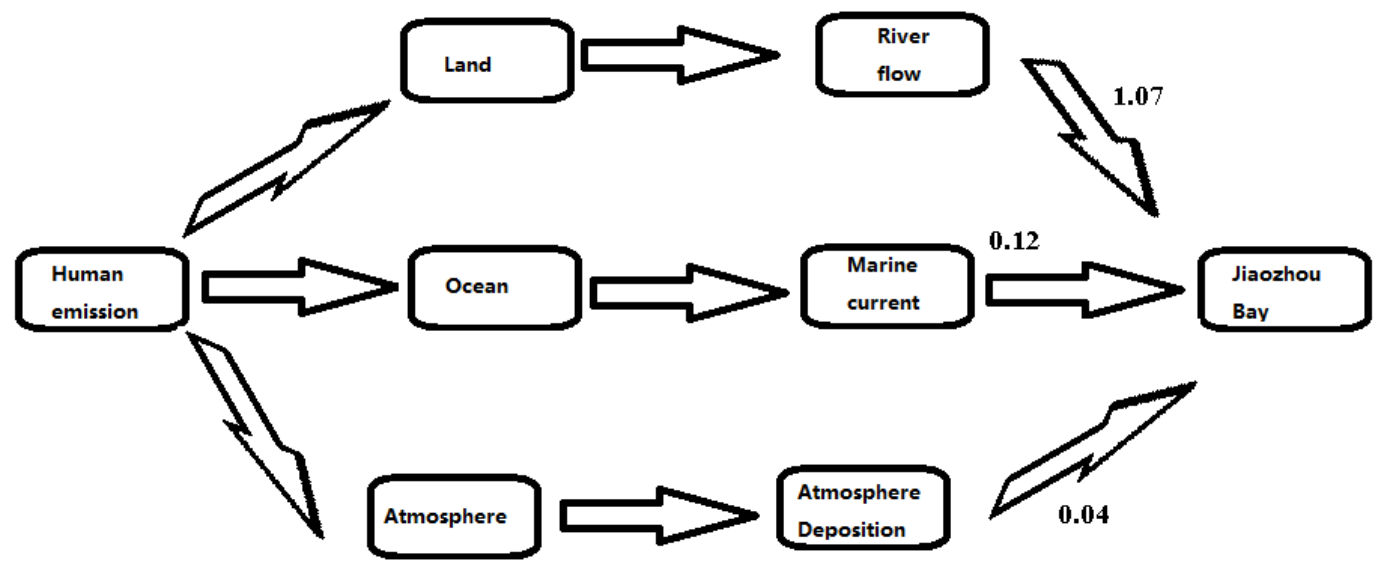

Fig. 5 Block diagram model for migration process of $\mathrm{Cd} / \mu \mathrm{g} \mathrm{L}-1$

\section{Conclusion}

Cd contents in surface waters in Jiaozhou Bay in April, July and October 1988 were 0.09-0.12 $\mu \mathrm{g}$ $\mathrm{L}^{-1}, 0.10-1.07 \mu \mathrm{g} \mathrm{L}{ }^{-1}$ and $0.03-0.040 \mu \mathrm{g} \mathrm{L}^{-1}$, respectively. The pollution levels of Cd in Jiaozhou Bay in 1988 were still slight. Cd contents in Jiaozhou Bay were in order of summer>spring >autumn, and in different seasons were different in one order of magnitude.

The major sources of $\mathrm{Cd}$ were river flow, marine current, and atmospheric deposition, respectively. The source strength of river flow was about one order of magnitude higher than the source strength of marine current, and the source strength of marine current was about one order of magnitude higher than the source strength of atmosphere deposition. River flow was the major Cd source in 1988 since a big part of Cd generated by human activities were washed to and delivered by river flow, and discharged to marine bay finally.

\section{Acknowledgement}

This research was sponsored by the China National Natural Science Foundation (31560107), Doctoral Degree Construction Library of Guizhou Nationalities University and Research Projects of Guizhou Nationalities University ([2014]02), Research Projects of Guizhou Province Ministry of Education (KY [2014] 266), Research Projects of Guizhou Province Ministry of Science and Technology (LH [2014] 7376).

\section{References}

[1] Yang DF and Miao ZQ: Marine Bay Ecology (I): Beijing, Ocean Precess, (2010), p. 1-320. (in Chinese)

[2] Yang DF and Gao ZH: Marine Bay Ecology (II): Beijing, Ocean Precess, (2010), p. 1-330. (in 
Chinese)

[3] Yang DF, Chen Y, Wang H, et al.: Coastal Engineering, Vol. 29 (2010), p. 73-82.

[4] Yang DF, Chen Y, Liu CX, et al.: Coastal Engineering, Vol. 32(2013), p. 68-78.

[5] Yang DF, Zhu SX, Wu YF, et al.: Applied Mechanics and Materials, Vol.644-650 (2014), p. 5325-5328.

[6] Yang DF, Wang FY, Wu YF, et al.: Applied Mechanics and Materials, Vol.644-650 (2014), p. 5329-5312.

[7] Yang DF. Chen Y, Gao ZH, et al.: Proceedings of the 2015 international symposium on computers and informatics. Vol. (2015), p. 2667-2674.

[8] Yang DF, Chen Y, Gao ZH, et al.: Chinese Journal of Oceanology and Limnology, Vol. 23(2005), p. 72-90. (in Chinese)

[9] Yang DF, Wang FY, Gao ZH, et al. Marine Science, Vol. 28 (2004), p. 71-74. (in Chinese)

[10] China's State Oceanic Administration: The specification for marine monitoring (Ocean Press, Beijiang 1991), p.1-300. (in Chinese) 